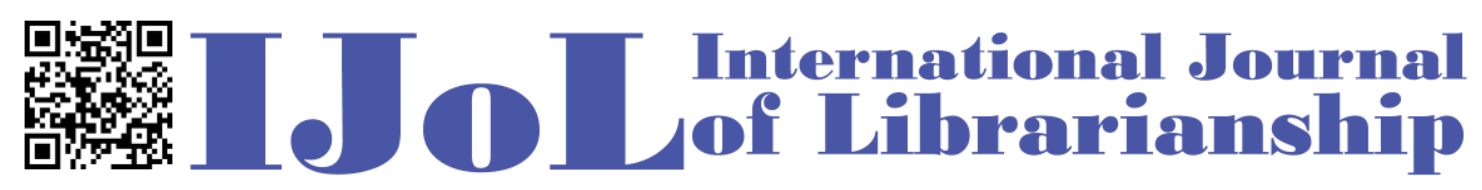

ISSN: 2474-3542 Journal homepage: http://journal.calaijol.org

\title{
A Bibliometric Study of Family Studies Journals Using Journal Impact Factors, CiteScore, and H-index
}

Zao Liu

\begin{abstract}
:
Although there are bibliometric studies of journals in various fields, the field of family studies remains unexplored. Using the bibliometric metrics of the two-year and five-year Journal Impact Factors, the H-index, and the newly revised CiteScore, this paper examines the relationships among these metrics in a bibliometric study of forty-four representative family studies journals. The citation data were drawn from Journal Citation Reports, Scopus, and Google Scholar. The correlation analysis found strong positive relationships on the metrics. Despite the strong correlations, discrepancies in rank orders of the journals were found. A possible explanation of noticeable discrepancy in rankings was provided, and the implications of the study for stakeholders were discussed.
\end{abstract}

To cite this article:

Liu, Z. (2021). A bibliometric study of family studies journals using Journal Impact Factors, CiteScore, and H-index. International Journal of Librarianship, 6(1), 1-12. https://doi.org/10.23974/ijol.2021.vol6.1.174

To submit your article to this journal:

Go to https://ojs.calaijol.org/index.php/ijol/about/submissions 


\title{
A Bibliometric Study of Family Studies Journals Using Journal Impact Factors, CiteScore, and $\mathrm{H}$-index
}

\author{
Zao Liu
}

Texas A\&M University, College Station, TX, USA

\begin{abstract}
Although there are bibliometric studies of journals in various fields, the field of family studies remains unexplored. Using the bibliometric metrics of the two-year and five-year Journal Impact Factors, the H-index, and the newly revised CiteScore, this paper examines the relationships among these metrics in a bibliometric study of forty-four representative family studies journals. The citation data were drawn from Journal Citation Reports, Scopus, and Google Scholar. The correlation analysis found strong positive relationships on the metrics. Despite the strong correlations, discrepancies in rank orders of the journals were found. A possible explanation of noticeable discrepancy in rankings was provided, and the implications of the study for stakeholders were discussed.
\end{abstract}

Keywords: Journal Impact Factor, CiteScore, H-index, Family Studies Journals, Bibliometric Study, Citation Analysis

\section{INTRODUCTION}

Bibliometrics is the application of statistical methods to analyze the research impact of books, journal articles, and other publications. Citation analysis is one of the most widely used bibliometric methods for examining frequency, patterns, and citation graphs of publications. For this bibliometric study, the following bibliometric metrics are used: (1) Journal Impact Factor (JIF/JIF5): Initiated by Eugene Garfield (1955) of the Institute for Scientific Information and acquired and currently owned by Clarivate Analytics, the Journal Impact Factor has been traditionally the predominant measure for assessing quality of journals. The Journal Impact Factor is based on the average number of citations received by articles published in the previous two or five years from a journal in a given citation year (Mingers, Macri, \& Petrovici, 2012). (2) H-index: Introduced by Jorge E. Hirsch in 2005, the H-index measures the productivity and impact of an author by giving the value $h$ to the author who has published $h$ papers that have been cited at least $h$ times (Hirsch, 2005). This method was used to measure the impact of journals (Braun, Glänzel, \& Schubert, 2006). (3) CiteScore (CS): Launched by Elsevier in December 2016, the CiteScore measures the average number of citations received in a given year by all articles published in the previous three years in a journal (James, Colledge, Meester, Azoulay, \& Plume, 2019). In June 
2020, Elsevier announced its change in the calculation of the CiteScore (Scopus, 2020). The new CiteScore measures the number of citations received by documents of a journal published during a four-year period divided by the number of documents published in the journal in the same time period. The citation window is increased to four years instead of one. It only includes peerreviewed documents such as articles, reviews, conference papers, book chapters, and data papers (Scopus, 2020).

The aforementioned bibliometric metrics are based on different databases: The Journal Impact Factor is based on Web of Science, the CiteScore is based on Scopus, and the H-index is based on Google Scholar. There are a number of differences among these databases. One major difference is their coverage. Web of Science core collection contains more than 21,100 peerreviewed scholarly journals over 250 academic disciplines, conference proceedings, and book data (Clarivate Analytics, 2020b) whereas Scopus holds 25,100 journal titles plus conference papers and book series (Elsevier, 2020). Adopting an inclusive and automated approach instead of using selection criteria for inclusion as Web of Science and Scopus do, Google Scholar practically indexes any scholarly document its robot crawlers can find on the academic web (Martin-Martin, Orduna-Malea, Thelwall, \& Delgado-Lopez-Cozar, 2019, December 3). The test of a sample of over 2,500 highly-cited documents across 252 subject categories by the authors indicates that the test favors Google Scholar in terms of coverage (Martin-Martin, et al., 2019). Other differences of interest here are languages of publications collected in the databases and types of literature included. Scopus covers 40 languages (Elsevier, 2020) whereas Web of Science includes about 50 languages (Clarivate Analytics, 2020c). Based on the information on its website, Google Scholar covers all languages in the world (Google Scholar, n.d.). Furthermore, Google Scholar indexes more types of literature than Web of Science and Scopus. Web of Science and Scopus typically index journal articles, conference papers, and books (Clarivate Analytics, 2020b; Elsevier, 2020). Google Scholar, however, includes journal articles, conference papers, theses and dissertations, academic books, pre-prints, abstracts, technical reports, and other scholarly literature from all broad areas of research (Google Scholar, n.d.). Given the differences in the citation resources and related metrics, especially the newly revised CS, which has not been compared to other metrics in previous studies, the relationships among the bibliometric metrics of the JIFs, CS, and H-index in journal evaluation are worth exploring. The purpose of this study is to examine the relationships among these metrics, using the unexplored family studies journals as an example for illustration.

\section{LITERATURE REVIEW}

Since the inceptions of the H-index in 2005 and CS in 2016, existing studies have focused on the correlations among the JIFs, CS and H-index for journals of various subject areas. In regard to the pair of the two-year JIF/five-year JIF and H-index, strong and moderate positive correlations have been found in different specialties such as forestry (Vanclay, 2008), business and management (Harzing \& van der Wal, 2009; Mingers, Macri, \& Petrovici, 2012), social work (Hodge \& Lacasse, 2011), soil science (Minasny, Hartemink, McBratney, \& Jang, 2013), and neurosurgery and spinal surgery (Yuen, 2018). Since the launch of the CiteScore in 2016, researchers have examined the relationships between the JIFs and CS. Among multiple metrics, positive relationships between the JIFs and CS have been observed in journals in remote sensing (Ahmad, Abdel-Magid, AbdelMagid, Bano, \& Waris, 2019), radiology, nuclear medicine and medical imaging (VillaseñorAlmaraz, Islas-Serrano, Murata, \& Roldan-Valadez, 2019), and occupational therapy, which 
correlated the two-year and five-year JIFs with the CS (Brown \& Gutman, 2019). Additionally, the JIF correlated strongly with the CS in computer science (Okagbue, Bishop, Adamu, Opanuga, \& Obasi, 2020), library and information science (Okagbue \& Teixeira da Silva, 2020), and telecommunication (Okagbue, Adamu \& Bishop, 2019).

There have been a number of studies comparing citations from Web of Science, Scopus, and Google Scholar. For example, one study compared the five-year citation counts of thirty-seven articles for the journal International Journal of Logistics Management from the three databases to identify the overlapping and unique citations (Chapman \& Ellinger, 2019). In their study, the authors found that the provenance of the unique Google Scholar citations was predominantly authentic scholarly literature and Google Scholar gave a more comprehensive representation of research impact and international scope than Web of Science and Scopus (Chapman \& Ellinger, 2019). Another study assessed nine South African environmental science journals for 2004-2008, focusing on citation counts, overlapping and unique citations, and inconsistency (Adriaanse \& Rensleigh, 2013). Their study indicated that Web of Science retrieved more citations than Google Scholar and Scopus. Google Scholar also retrieved the most inconsistencies whereas Scopus retrieved the least inconsistencies (Adriaanse \& Rensleigh, 2013). Based on the three databases, the authors also did a comprehensive evaluation of the journals in the same subject area for 20042008 at the macro and micro levels, including a broad range of categories such as content, access, searching, citation and analytic tools, references, and publication information (Adriaanse \& Rensleigh, 2011). Furthermore, Delgado and Repiso (2013) examined the h-index of 277 communication journals based on the citations drawn from the three resources. Their findings indicated that Google Scholar Metrics doubled the coverage, and provided higher h-indices than Web of Science and Scopus. They concluded that, like Web of Science and Scopus, Google Scholar is a valid and reliable tool for identifying the main communication journals (Delgado \& Repiso, 2013). Lastly, in their citation study of journals in a range of disciplines (Chinese studies, linguistics/computer science, inorganic chemistry, library \& information science, political science, virology) for the publication window 2010-2014 and the citation window 2010-June/July 2015, Moed, Bar-Ilan, and Halevi (2016) proposed a new methodology to compare Google Scholar and Scopus with a focus on indexing speed, citation counts, and duplicate citation counts. Their findings included the following: (1) The ratio of Google Scholar over Scopus citation differed across disciplines with Open Access journals higher than other journals. (2) Double citation counts in Google Scholar accounted for less than $2 \%$ of the cases. (3) There was a strong linear correlation (Pearson's r: 0.8-0.9) between Google Scholar and Scopus citation counts at the article level. (4) Compared with Google Scholar, the median Scopus indexing delay was about two months (Moed et al., 2016). Although the studies mentioned above offered great insights into the citation analysis of the databases, their main objectives were not to compare the bibliometric metrics of the JIF, JIF5, CS, and H-index.

Using the JIF, CS, and H-index, Chen, Geng, Zhong, Zhuang, \& Pan (2020) conducted a bibliometric analysis of ecosystem services, including the influential journals in the field. Nonetheless, their objective was to provide a comprehensive study of the ecosystem-related literature instead of comparing these three metrics in their journal evaluation. As mentioned earlier, Brown and Gutman compared a number of bibliometric indictors in occupational therapy journals, including the JIF, JIF5, CS, and H-index. However, their focus was on the comparisons among the JIF, JIF5 and CS, and among different kinds of H-indices (Brown \& Gutman, 2019). In their study of economics journals, Hirschberg and Lye (2020) used a number of biometric measures, including the JIF, JIF5, CS, and H-index. Their major objectives were to generate journal grades based on 
the grade distribution implied by the Australian Business Deans Council and to categorize the bibliometrics using cluster analysis. Thus, to the best of the author's knowledge, research comparing and correlating the four metrics from Web of Science, Scopus, and Google Scholar is scant.

This study aims to compare the four bibliometric metrics of the JIF, JIF5, CS, and H-index, using representative family studies journals as a sample. Previous studies of family studies literature primarily provided reviews on the specific themes or trends in the field, such as sex and sex research (Jones, Johnson, Wenglein, \& Elshershaby, 2019), stepparent-child relationship quality (Jensen \& Howard, 2015), work and family (Perry-Jenkins \& Gerstel, 2020), or an evaluation of a particular journal such as Journal of Family and Economic Issues (Dew, 2008). Although there were some bibliometric studies of the family studies literature, they focused on global research trends on child maltreatment (Tran et al., 2018), global research trends and performance in family therapy (Lou \& Lin, 2012) or a bibliometric analysis of a single journal (Bayer, 1982). Thus, comprehensive assessments of family studies journals are lacking.

To fill the gaps, this study provides a systematic evaluation of family studies journals by exploring the relationships among the metrics of the JIF, JIF5, CS, and H-index while ranking the journals, using data from Web of Science, Scopus, and Google Scholar. The value of this study is fourfold. First, it aims to correlate the relationships between the JIF, JIF5, H-index, and the newly revised CS, which is an interesting metric to explore after its revision. Second, family studies is an important subject area in social sciences. It studies family as a vital social institution for our society, and deals with important issues such as marriage, parenting, childhood, family structure, family relationships, and family therapy, to name just a few. Third, the results of the study can serve as recommendations for faculty members, academic administrators, and academic librarians in identifying family studies journals for the purposes of publication, tenure and promotion, and collection development. Fourth, the comparison of the different metrics in this study can add to the testing of these metrics as tools for measuring the impact of journals.

\section{METHODOLOGY}

The study addresses the following research questions: (1) To what extent are these bibliometric metrics correlated with one another in the selected family studies journals? (2) What are the rankings of these journals by these metrics? (3) Are there any discrepancies in the journals' rank orders by these metrics and why?

Forty-seven journals were retrieved from the family studies category of the 2019 Journal Citation Reports in the Web of Science. The corresponding journals were selected by title search in Scopus and Google Scholar. The titles were searched separately on Scopus Preview website (Elsevier, n.d.) whereas the same titles were searched one by one on Publish or Perish, version 7.27 (Harzing, 2020) for Google Scholar titles. The Journal of Family Planning and Reproductive Health Care changed its title to BMJ Sexual \& Reproductive Health in 2018. Because there were no combined 2019 JIFs values for the two titles, they were dropped from the study. Zeitschrifte fur Familienforschung was also dropped because it did not have the CS value for 2019 in Scopus.

In total, forty-four family studies journals were included in the study. The values of the two-year JIF were extracted from the 2019 JCR for the forty-four journals whereas the values of the five-year journal impact factor were only available for forty-two journals (Clarivate Analytics, 
2020a.) The 2019 CS values were retrieved from Scopus Preview website (Elsevier, n.d.) by manually checking each individual journal separately. The search result carried the CS value for each title automatically. The H-index values were computed from Google Scholar, using Harzing's Publish or Perish (Harzing, 2020). A four-year publication window (2016-2019), which corresponds to the publication window of the 2019 CS, was used for the H-index retrieval. The data was collected from October 1, 2020 to October 2, 2020. When the title search did not work properly for a particular journal, its title and ISSN were used for the search. The search results of the H-index values were visually inspected for their accuracy and relevancy. The means of the four metrics were obtained to show the central tendency. The rank orders of the journals by the different metrics were presented and compared. A Spearman correlation analysis was conducted on these metrics using SPSS. Scatter plots showing the correlations by the metrics were also provided.

\section{RESULTS}

Table 1 shows the statistics of the JIF, JIF5, CS, and H-index and the rankings of the forty-four family studies journals. The mean JIF for these journals was 1.645. The mean JIF5 was 2.073 and the mean CS was 2.925. Trauma, Violence, \& Abuse, Future of Children and Perspectives on Sexual and Reproductive Health were the top three journals ranked by the JIF, JIF5 and CS. The mean H-index was 22.91, with Child Abuse \& Neglect ranked first (52), Trauma, Violence, \& Abuse second (47), and Journal of Interpersonal Violence third (46). On average, the H-index value was the highest, followed by the CS value, JIF5 value and JIF value.

It is interesting to note the obvious difference in rank orders for a number of journals by the metrics. Compared to the rankings by the JIF, JIF5, and CS, some journals were ranked lower by the H-index. For example, Future of Children was ranked second by the JIF, JIF5, and CS, but 15 th by the H-index. Perspectives on Sexual and Reproductive Health was ranked third by the JIF, JIF5, and CS, but 26th by the H-index. Journal of Early Adolescence was ranked 13th by the JIF, JIF5, and CS, but 21st by the H-index. On the other hand, there were journals which were ranked lower by the JIF, JIF5, and CS, but higher by the H-index. Examples include Child Abuse \& Neglect (first by the H-index, 6th by the JIF and JIF5, and 8th by the CS), Children and Youth Services Review (fourth by the H-index, 18th by the JIF, 22nd by the JIF5, and 24th by the CS), Journal of Child and Family Studies (5th by the H-index, 23rd by the JIF, 21st by the JIF5, and 20th by the CS), and Journal of Family Issues (8th (tied) by the H-index, 25th by the JIF, 24th by the JIF5, and 26th by the CS).

Table 1. Family Studies journals ranked by JIF, JIF5, CS and H-index

\begin{tabular}{|c|c|c|c|c|c|c|c|c|}
\hline Journal Title & JIF & Rank & JIF5 & Rank & CS & Rank & $\mathrm{H}$ & Rank \\
\hline Trauma, Violence, \& Abuse & 6.325 & 1 & 6.525 & 1 & 9 & 1 & 47 & 2 \\
\hline $\begin{array}{l}\text { Future of Children } \\
\text { Perspectives on Sexual and Reproductive }\end{array}$ & 5.133 & 2 & 4.789 & 2 & 6.1 & 2 & 25 & 15 \\
\hline Health & 3.636 & 3 & 4.019 & 3 & 5.4 & 3 & 18 & 26 \\
\hline Journal of Interpersonal Violence & 3.573 & 4 & 3.115 & 7 & 4.1 & 9 & 46 & 3 \\
\hline Child Maltreatment & 2.9 & 5 & 3.587 & 5 & 3.9 & 11 & 26 & 14 \\
\hline
\end{tabular}


Child Abuse \& Neglect

Psychology of Violence

Journal of Social and Personal

Relationships

Journal of Family Theory \& Review

Journal of Marriage and Family

Family Process

Culture, Health \& Sexuality

Journal of Early Adolescence

Journal of Research on Adolescence

Journal of Family Nursing

Journal of Family Psychology

Journal of Sex \& Marital Therapy

Children and Youth Services Review

Journal of Marital and Family Therapy

Journal of Family Violence

Child \& Family Social Work

Family Relations

Journal of Child and Family Studies

Families Systems \& Health

Journal of Family Issues

Child Abuse Review

Journal of Family Studies

Parenting: Science and Practice

Journal of Aggression Maltreatment \&

Trauma

Emerging Adulthood

Journal of Child Sexual Abuse

History of the Family

Family \& Community Health

International Journal of Law, Policy and the Family

Journal of Family and Economic Issues

Child Welfare

Journal of Family Therapy

Families in Society

Families, Relationships and Societies

American Journal of Family Therapy

Child \& Family Behavior Therapy

Journal of Family History

Australian and New Zealand Journal of

Family Therapy

Journal of Comparative Family Studies

\begin{tabular}{rrrrrrrr}
2.569 & 6 & 3.297 & 6 & 4.4 & 8 & 52 & 1 \\
2.381 & 7 & 2.977 & 9 & 5.3 & 4 & 36 & 7 \\
& & & & & & & \\
2.359 & 8 & 2.436 & 14 & 2.5 & 24 & 28 & 13 \\
2.328 & 9 & 3.031 & 8 & 3.9 & 11 & 25 & 15 \\
2.215 & 10 & 3.595 & 4 & 4.5 & 7 & 38 & 6 \\
2.175 & 11 & 2.764 & 10 & 5.2 & 5 & 32 & 8 \\
1.969 & 12 & 2.421 & 16 & 3.1 & 17 & 25 & 15 \\
1.924 & 13 & 2.454 & 13 & 3.5 & 13 & 23 & 21 \\
1.905 & 14 & 2.646 & 12 & 4.8 & 6 & 30 & 12 \\
1.889 & 15 & 2.431 & 15 & 2.8 & 20 & 18 & 26 \\
1.836 & 16 & 2.727 & 11 & 4.1 & 9 & 31 & 10 \\
1.775 & 17 & 2.052 & 18 & 2.8 & 20 & 22 & 22 \\
1.521 & 18 & 1.87 & 22 & 2.5 & 24 & 45 & 4 \\
1.421 & 19 & 1.846 & 23 & 2.9 & 18 & 24 & 19 \\
1.357 & 20 & 1.63 & 25 & 2.2 & 27 & 25 & 15 \\
1.337 & 21 & 1.62 & 26 & 3.2 & 16 & 31 & 10 \\
1.317 & 22 & 1.965 & 20 & 3.3 & 14 & 24 & 19 \\
1.31 & 23 & 1.925 & 21 & 2.8 & 20 & 42 & 5 \\
1.289 & 24 & 1.589 & 27 & 1.8 & 31 & 16 & 30 \\
1.249 & 25 & 1.772 & 24 & 2.4 & 26 & 32 & 8 \\
1.19 & 26 & 1.982 & 19 & 3.3 & 14 & 18 & 26 \\
1.179 & 27 & 1.351 & 29 & 1.8 & 31 & 13 & 32 \\
1.156 & 28 & 2.358 & 17 & 2.7 & 23 & 13 & 32 \\
& & & & & & & \\
1.03 & 29 & 1.086 & 31 & 1.7 & 35 & 17 & 29 \\
0.974 & 30 & $\mathrm{n} / \mathrm{a}$ & $\mathrm{n} / \mathrm{a}$ & 2.9 & 18 & 20 & 23 \\
0.929 & 31 & 1.411 & 28 & 1.9 & 30 & 19 & 25 \\
0.925 & 32 & 0.949 & 33 & 1.5 & 37 & 12 & 37 \\
0.897 & 33 & 1.322 & 30 & 1.8 & 31 & 13 & 32 \\
& & & & & & & \\
0.875 & 34 & 0.72 & 39 & 1.5 & 37 & 9 & 39 \\
0.787 & 35 & $\mathrm{n} / \mathrm{a}$ & $\mathrm{n} / \mathrm{a}$ & 2 & 28 & 20 & 23 \\
0.723 & 36 & 0.783 & 38 & 1.1 & 40 & 8 & 42 \\
0.697 & 37 & 0.934 & 35 & 2 & 28 & 15 & 31 \\
0.691 & 38 & 1.024 & 32 & 1.3 & 39 & 13 & 32 \\
0.672 & 39 & 0.861 & 36 & 1.6 & 36 & 13 & 32 \\
0.564 & 40 & 0.833 & 37 & 1 & 41 & 9 & 39 \\
0.52 & 41 & 0.942 & 34 & 1.8 & 31 & 9 & 39 \\
0.318 & 42 & 0.368 & 42 & 0.8 & 42 & 7 & 43 \\
0.267 & 44 & 0.59 & 40 & 0.7 & 44 & 7 & 43 \\
& & & & & & & \\
\hline & & & & & & &
\end{tabular}


Table 2 shows the Spearman's correlation coefficients of the four metrics for the selected journals. The JIF was highly correlated with the JIF5 $(\rho=0.957, p<.001)$, the CS $(\rho=0.897, p$ $<.001)$, and the H-index $(\rho=0.806, \mathrm{p}<.001)$. There were also strong positive correlations between the CS and H $(\rho=0.797, p<.001)$, the JIF5 and H $(\rho=0.784, p<.001)$, and the JIF5 and CS $(\rho=0.948, p<.001)$. The strong associations among the metrics are illustrated in the scatter plot matrix (Figure 1). The shapes of the data points indicated that the JIF, JIF5, and CS had closer associations among themselves than with the H-index.

Table 2. Spearman's rho correlations among JIF $(n=44)$, JIF5 ( $n=42)$, CS $(n=44)$ and H $(n=44)$

\begin{tabular}{|c|c|c|c|c|}
\hline & JIF & JIF5 & $\mathrm{CS}$ & $\mathrm{H}$ \\
\hline JIF & 1 & & & \\
\hline JIF5 & $0.957 *$ & 1 & & \\
\hline CS & $0.897^{*}$ & $0.948^{*}$ & 1 & \\
\hline $\mathrm{H}$ & $0.806^{*}$ & $0.784 *$ & $0.797 *$ & 1 \\
\hline
\end{tabular}

$* \mathrm{p}<.001$

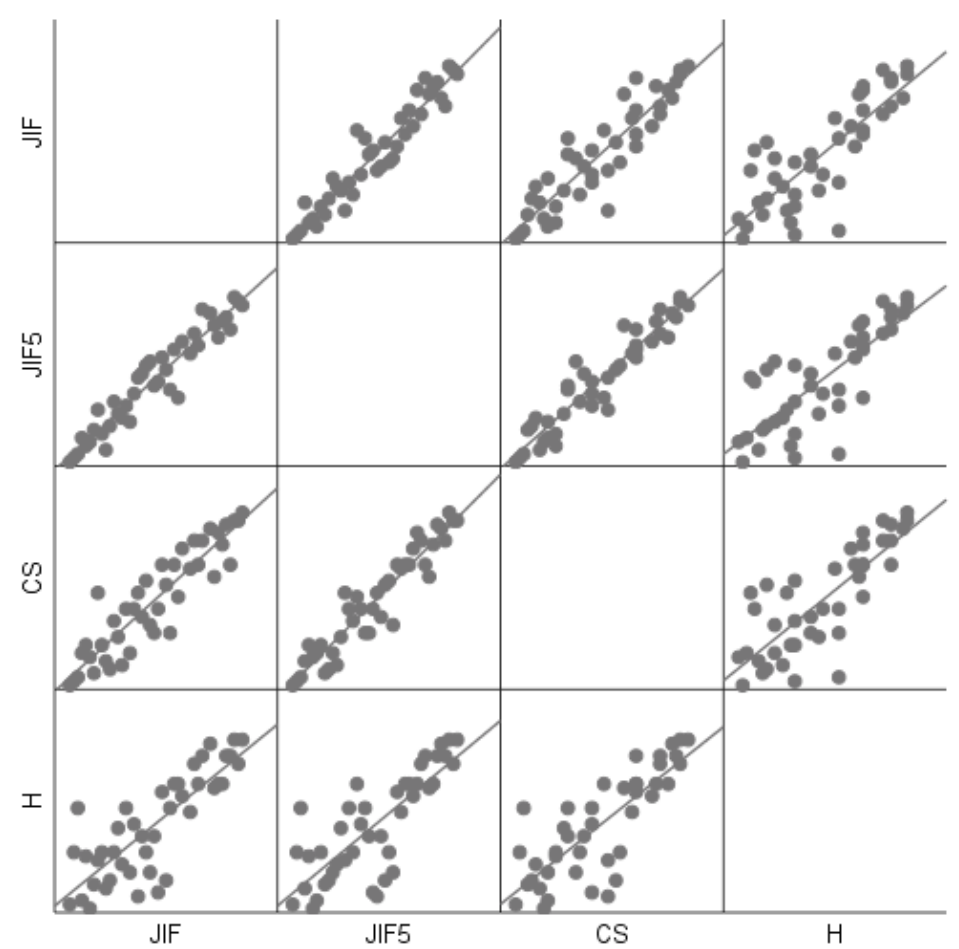

Figure 1. Scatter plots showing the correlations among JIF, JIF5, CS, and H-index 


\section{DISCUSSION}

This study examined the relationships among the JIF, JIF5, CS, and H-index in terms of ranking family studies journals. To achieve this aim, the rank orders of the journals were presented and compared and a Spearman's correlation was conducted of the metrics. It was found that the four metrics were all highly correlated, indicating strong associations among measures for these journals. This finding is consistent with previous studies in other subject areas. As mentioned earlier, high correlations between the JIF/JIF5 and H-index have been reported in journals in various fields, for example, in forestry (Vanclay, 2008), business and management (Harzing \& van der Wal, 2009), social work (Hodge \& Lacasse, 2011), and soil science (Minasny, Hartemink, McBratney, \& Jang, 2013). The JIF or JIF5 and CS correlated well with journals in radiology, nuclear medicine and medical imaging (Villaseñor-Almaraz, et al., 2019), occupational therapy (Brown \& Gutman, 2019), computer science (Okagbue, et al., 2020), and library and information science (Okagbue \& Teixeira da Silva, 2020). Despite the differences in Web of Science, Scopus, and Google Scholar as data sources, the rankings of the family studies journals by the metrics corresponded well. It is interesting to note that the newly revised CS also correlated well with the other metrics in this study. The high correlations among the JIF, JIF5, CS, and H-index in this study added to the testimony that the CS and $\mathrm{H}$-index can serve as alternative tools for measuring journal quality.

The top ranked journals are also published by well-known publishers and professional institutes and societies. For example, Trauma, Violence, \& Abuse, Journal of Interpersonal Violence, Child Maltreatment, Journal of Social and Personal Relationships are published by Sage Publications; Future of Children is published by Woodrow Wilson School of Public and International Affairs at Princeton University and the Brookings Institution; Perspectives on Sexual and Reproductive Health and Family Process are published by Wiley-Blackwell on behalf of Guttmacher Institute and the Family Process Institute, respectively; Journal of Family Theory \& Review and Journal of Marriage and Family are also published by Wiley-Blackwell on behalf of the National Council on Family Relations; Child Abuse \& Neglect, the official journal of the International Society for Prevention of Child Abuse and Neglect, is published by Elsevier; and Psychology of Violence is published by the American Psychological Association.

As mentioned earlier, despite high correlations among the metrics for the journals, the rank orders of some journals differed noticeably. For example, four out of the top five journals ranked by the H-index (Child Abuse \& Neglect, Journal of Interpersonal Violence, Children and Youth Services Review, and Journal of Child and Family Studies) claimed higher places than those ranked by the JIF, JIF5, and CS. The exception was Trauma, Violence, \& Abuse, which publishes many reviews articles, which usually attract more citations. A possible explanation for the discrepancy is that these four journals publish a large number of articles each year, including highly cited articles. This increases their chance of obtaining high $\mathrm{H}$-index values in Google Scholar (Harzing \& van der Wal, 2009). On the other hand, if journals publish a limited number of articles, their $\mathrm{H}-$ index values may be lower compared with their JIF, JIF5, and CS values. Cases in point were Future of Children (ranked 2nd by the JIF, JIF5, and CS, but 15th by the H-index), and Perspectives on Sexual and Reproductive Health (ranked 3rd by the JIF, JIF5, and CS, but 26th by the H-index). 


\section{CONCLUSIONS}

To sum up, this study contributes to the current research in bibliometric study by exploring the relationships among the JIF, JIF5, CS, and H-index through representative family studies journals. The study is the first to provide a systematic evaluation of the family studies journals using these major bibliometric metrics. In addition, the use of the newly revised CiteScore metric for correlation analysis in this study provides a useful case study for future research in this regard. The study shows that all four bibliometric metrics correlate well with the family study journals even though the newly revised CS is used. The correlation analysis among the metrics may be of special interest to researchers due to the recent change in the CS and the H-index values drawn from Google Scholar. On the other hand, this study reveals that the correlations among the JIF, JIF5, and CS tend to be stronger than those with the H-index. Also, this study demonstrates that the discrepancy in rank orders can be caused by high $\mathrm{H}$-index values for journals which publish a large number of papers with possible highly-cited ones, or lower H-index values from journals which publish a limited number of papers each year.

A limitation of this study is that the journals under study were confined to those in the family studies category of the 2019 JCR and their counterparts collected separately from Scopus and Google Scholar. Due to the different selection criteria for JCR by Clarivate Analytics' Web of Science, some journals dealing with family studies may not have been included in this study. Another limitation concerns the languages of the selected journals. Almost all the family studies journals listed in the 2019 JCR are published in English except for Zeitschrifte fur Familienforschung, which was dropped from this study due to the unavailability of its citation data for the targeted years in Scopus. Therefore, it is very likely that important family studies journals in other languages are missing in this study.

Finally, professional stakeholders may benefit from the findings of this study. Researchers in family studies may use the findings to identify appropriate journals for manuscript submissions. As the ranking of the journals by the $\mathrm{H}$-index is based on the number of highly cited papers and those by the JIF, JIF5, and CS are based on the average citations per paper, the different rankings provide researchers with opportunities to choose journals that meet their needs. The principle may also apply to academic librarians in collecting journals in family studies and fund allocation. Depending on the available budget, academic librarians may choose journals with overall influence or do it at their discretion. Last but not least, the findings of this study may be of interest to academic administrators in considering tenure and promotion cases for their institutions.

\section{References}

Adriaanse, L. S., \& Rensleigh, C. (2011). Comparing Web of Science, Scopus and Google Scholar from an environmental sciences perspective. South African Journal of Libraries and Information Science, 77(2), 169-178. https://doi.org/10.7553/77-2-58

Adriaanse, L. S., \& Rensleigh, C. (2013). Web of Science, Scopus and Google Scholar: A content comprehensiveness comparison. The Electronic Library, 31(6), 727-744. https://doi.org/10.1108/EL-12-2011-0174

Ahmad, S., Abdel-Magid, H. I. M., Abdel-Magid, I. M., Bano, E., \& Waris, A. (2019). An analogy in scientometric journal factors of importance of remote sensing journals. Journal of Scientometric Research, 8(2), 79-85. DOI:10.5530/jscires.8.2.13 
Bayer, A. E. (1982). A bibliometric analysis of marriage and family literature. Journal of Marriage and Family, 44(3), 527-538. DOI: 10.2307/351577

Braun, T., Glänzel, W., \& Schubert, A. (2006). A Hirsch-type index for journals. Scientometrics, 69(1), 169-173. https://doi.org/10.1007/s11192-006-0147-4

Brown, T., \& Gutman, S. A. (2019). A comparison of bibliometric indicators in occupational therapy journals published in English. Canadian Journal of Occupational Therapy, 86(2), 125-135. DOI: 10.1177/0008417419831453

Chapman, K., \& Ellinger, A. E. (2019). An evaluation of Web of Science, Scopus and Google Scholar citations in operations management. The International Journal of Logistics Management, 30(4), 1039-1053. https://doi.org/10.1108/IJLM-04-2019-0110

Chen, W., Geng, Y., Zhong, S., Zhuang, M, \& Pan, H. (2020). A bibliometric analysis of ecosystem services evaluation from 1997 to 2016. Environmental Science and Pollution Research, 27, 23503-23513. https://doi.org/10.1007/s11356-020-08760-x

Clarivate Analytics. (2020a). Journal Citation Reports. Web of Science. Retrieved from https://clarivate.com/webofsciencegroup/solutions/journal-citation-reports/

Clarivate Analytics. (2020b). Web of Science Core Collection. Web of Science. Retrieved from https://clarivate.com/webofsciencegroup/solutions/web-of-science-core-collection/

Clarivate Analytics. (2020c). Web of Science Core Collection Help. Web of Science. Retrieved from http://images.webofknowledge.com.srv-proxy1.library.tamu.edu//WOKRS535R111 /help/WOS/hs_language.html

Delgado, E., \& Repiso, R. (2013). The impact of communication journals: Comparing Google Scholar Metrics, Web of Science and Scopus. Comunicar, 21(41), 45-52. https://doi.org/10.3916/C41-2013-04

Dew, J. (2008). Themes and trends of Journal of Family and Economic Issues: A review of twenty years (1988-2007). Journal of Family and Economic Issues. 29, 496-540. DOI 10.1007/s10834-008-9118-7

Elsevier. (n.d.). Sources. Scopus Preview. Retrieved from https://www.scopus.com/sources

Elsevier. (2020). Scopus Content Coverage Guide. Scopus Preview. Retrieved from https://www.elsevier.com/?a=69451

Garfield, E. (1955). Citation indexes for science: A new dimension in documentation through association of ideas. Science, 122(3159), 108-111.

Google Scholar. (n.d.). Inclusion. Google Scholar. Retrieved from https://scholar.google.com/intl/en/scholar/inclusion.html\#content

Harzing, A. W. (2020). Publish or Perish. Retrieved from http://www.harzing.com/pop.htm

Harzing, A.W., \& van der Wal, R. (2009). A Google Scholar h-index for journals: An alternative metric to measure journal impact in economics and business. Journal of the American Society for Information Science and Technology, 60(1), 41-46. https://doi.org/10.1002/asi.20953

Hirsch, J. E. (2005). An index to quantify an individual's scientific research output. Proceedings of the National Academy of Sciences of the United States of America, 102(46), 1656916572. https://doi.org/10.1073/pnas.0507655102

Hirschberg, J. G., \& Lye, J. N. (2020). Grading journals in economics: The ABCS of the ABDC. Journal of Economic Surveys, 34(4), 876-921. DOI: 10.1111/joes.12369

Hodge, D. R., \& Lacasse, J. R. (2011). Ranking disciplinary journals with the Google Scholar hindex: A new tool for constructing cases for tenure, promotion, and other professional 
decisions. Journal of Social Work Education, 47(3), 579-596. https://doi.org/10.5175/JSWE.2011.201000024

James, C., Colledge, L., Meester, W., Azoulay, N., \& Plume, A. (2019). CiteScore metrics: Creating journal metrics from the Scopus citation index. Learned Publishing, 32, 367-374. DOI: $10.1002 /$ leap. 1246

Jensen, T. M., \& Howard, M. O. (2015). Perceived stepparent-child relationship quality: A systematic review of stepchildren's perspectives. Marriage \& Family Review, 51(2), 99153. DOI: $10.1080 / 01494929.2015 .1006717$

Jones, A. C., Johnson, N. C., Wenglein, S., \& Elshershaby, S. T. (2019). The state of sex research in MFT and family studies literature: A seventeen-year content analysis. Journal of Marital and Family Therapy, 45(2), 275-295. DOI: 10.1111/jmft. 12344

Lou, Y. C., \& Lin, H. F. (2012). Estimate of global research trends and performance in family therapy in Social Science Citation Index. Scientometrics, 90, 807-823. DOI 10.1007/s11192-011-0549-9

Martin-Martin, A., Orduna-Malea, E., Thelwall, M., \& Delgado-Lopez-Cozar, E. (2019, December 3). Google Scholar, Web of Science, and Scopus: Which is best for me? Impact of Social Sciences Blog. [Blog post]. Retrieved from http://eprints.lse.ac.uk/103443/

Minasny, B., Hartemink, A. E., McBratney, A., \& Jang, H. J. (2013). Citations and h index of soil researchers and journals in the Web of Science, Scopus, and Google Scholar. PEERJ, 1, e183. https://doi.org/10.7717/peerj.183

Mingers, J., Macri, F., \& Petrovici, D. (2012). Using the h-index to measure the quality of journals in the field of business and management, Information Processing and Management, 48(2), 234-241. https://doi.org/10.1016/j.ipm.2011.03.009

Moed, H. F., Bar-Ilan, J., \& Halevi, G. (2016). A new methodology for comparing Google Scholar and Scopus. Journal of Informetrics, 10(2), 533-551. https://doi.org/10.1016/j.joi.2016.04.017

Okagbue, H. I., Adamu, P. I., \& Bishop, S. A. (2019). Curve estimation models for estimation and prediction of Impact Factor and CiteScore using the journal percentiles: A case study of telecommunication journals. International Journal of Online and Biomedical Engineering, 15(14), 31-40. https://doi.org/10.3991/ijoe.v15i14.11373

Okagbue, H. I., Bishop, S. A. Adamu, P. I., Opanuga, A. A., \& Obasi, E. C. M. (2020). Analysis of percentiles of computer science, theory and methods journals: CiteScore versus Impact Factor. DESIDOC Journal of Library \& Information Technology, 40(1), 11-17. DOI: $10.14429 /$ djlit.40.1.14866

Okagbue, H. I., \& Teixeira da Silva, J. A. (2020). Correlation between the CiteScore and Journal Impact Factor of top-ranked library and information science journals. Scientometrics, 124, 797-801. https://doi.org/10.1007/s11192-020-03457-x

Perry-Jenkins, M., \& Gerstel, N. (2020). Work and family in the second decade of the 21 st century. Journal of Marriage and Family, 82, 420-453. DOI:10.1111/jomf.12636

Scopus, (2020, June 9). CiteScore 2019 now LIVE! [Blog post]. Retrieved from: https://blog.scopus.com/posts/citescore-2019-now-live

Tran, B. X., Pham, T. V, Ha, G. H., Ngo, A. T., Nguyen, L. H., Vu, T. T. M., Do, H. N., .. Ho, R. C. M. (2018). A bibliometric analysis of the global research trend in child maltreatment. International Journal of Environmental Research and Public Health, 15, 1456. DOI:10.3390/ijerph15071456 
Vanclay, J. K. (2008). Ranking forestry journals using the h-index. Journal of Informetrics, 2(4), 326-334. https://doi.org/10.1016/j.joi.2008.07.002

Villaseñor-Almaraz, M., Islas-Serrano, J., Murata, C., \& Roldan-Valadez, E. (2019). Impact factor correlations with Scimago Journal Rank, Source Normalized Impact per Paper, Eigenfactor Score, and the CiteScore in radiology, nuclear medicine \& medical imaging journals. $L a$ Radiologia Medica, 124, 495-504. https://doi.org/10.1007/s11547-019-00996-Z

Yuen, J. (2018). Comparison of Impact Factor, Eigenfactor metrics, and SCImago Journal Rank indicator, and $\mathrm{H}$-index for neurosurgical and spinal surgical journals. World Neurosurgery, 119, e328-e337.

\section{About the author}

Zao Liu is a metadata and cataloging librarian at Texas A\&M University Libraries. His research interests include bibliometrics, information seeking and usage, and Chinese studies. 